\title{
Managing Water Resources on Long Island, New York, with Integrated, Multidisciplinary Science
}

\section{Introduction}

Nutrients, harmful algal blooms, and synthetic chemicals like per- and polyfluoroalkyl substances (PFAS) and 1,4-dioxane threaten Long Island's water resources by affecting the quality of drinking water and ecologically sensitive habitats that support the diverse wildlife throughout the island. Understanding the occurrence, fate, and transport of these potentially harmful chemicals is critical to protect these vital resources. The U.S. Geological Survey (USGS) is collecting and analyzing data to support informed water-resource management decisions. This fact sheet introduces ongoing efforts and future areas of study aimed to help water professionals develop a comprehensive science strategy to address contamination of the Long Island aquifer system, the sole source of drinking water for nearly 3 million people. These studies include surface and groundwater collection and groundwater flow modeling. Funding for the data collection has been provided by the USGS, New York State Department of Environmental Conservation, New York City Department of Environmental Protection, Suffolk County Water Authority, Nassau County Department of Public Works, State and local agencies, and Tribal and Federal partners. Without the foresight and long-term commitment of these funding partners, evaluating sustainability and planning for future water needs would not be possible.

\section{Sustainability}

People living on Long Island get their drinking water from one of three principal aquifers. From the shallowest to the deepest, these are the upper glacial, Magothy, and Lloyd aquifers (fig. 1). Together, these aquifers make up a sole-source aquifer system. A sole source aquifer is an aquifer that is used for more than 50 percent of the total drinking water in its area, and which has no alternative should it become contaminated (U.S. Environmental Protection Agency, 2020).

Today, groundwater is pumped out of Long Island's sole-source aquifer system by about 50 water suppliers in Nassau and Suffolk Counties. As the demand for water increases, more water is pumped. There are concerns that the quality and quantity of the water supply may not be enough to meet both human and ecological needs. These concerns are made worse as climate change continues to alter the environment.

To address these concerns, the USGS, in cooperation with the New York State Department of Environmental Conservation, began a study in 2016 to find if the Long Island aquifer system can sustain the current and projected groundwater withdrawals. A sustainable level of groundwater use requires a balance between human and environmental needs.

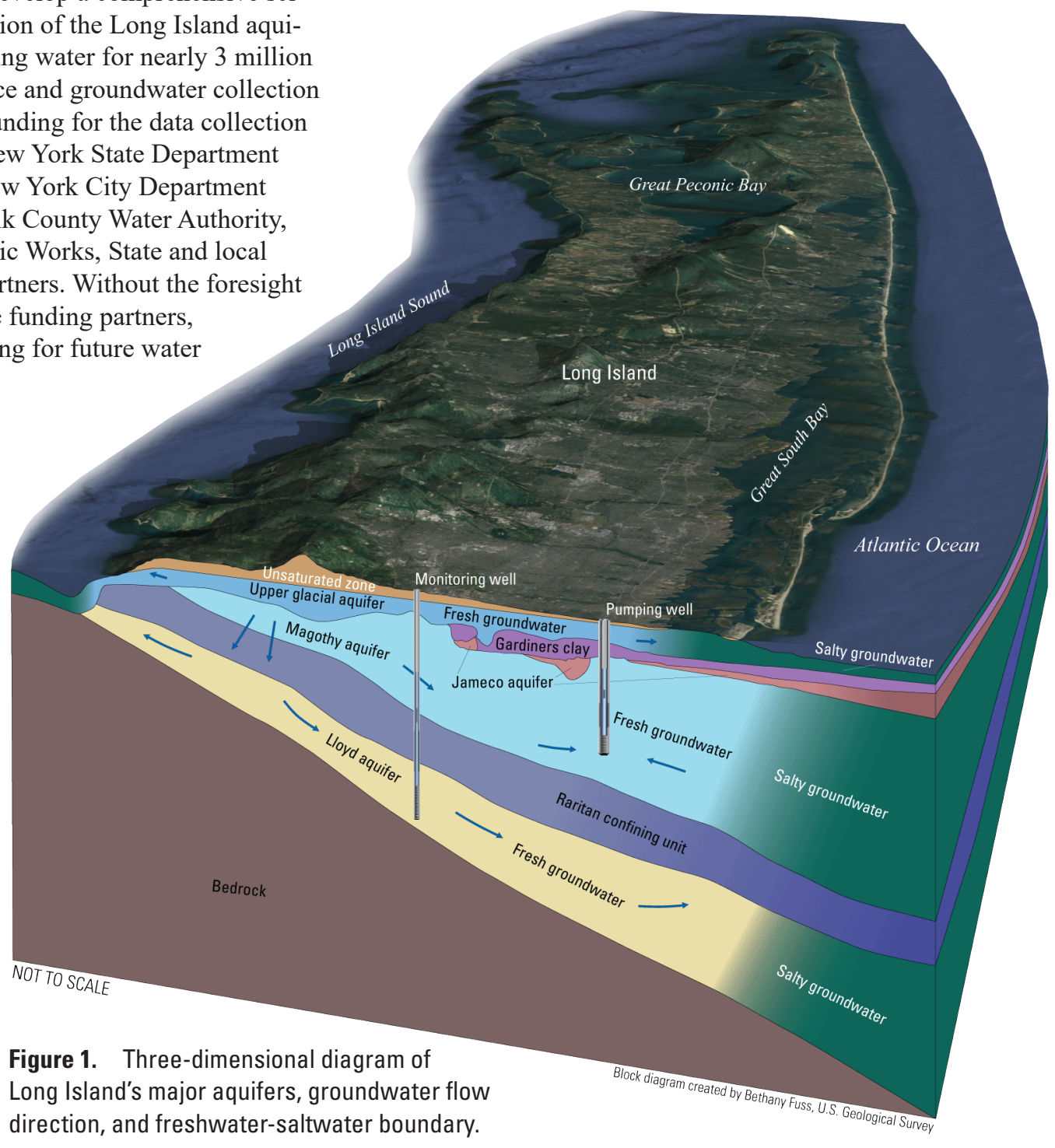
Long Island's major aquifers, groundwater flow direction, and freshwater-saltwater boundary. 
As part of this ongoing (2021) study of Long Island's groundwater sustainability, the USGS is developing a cuttingedge numerical groundwater-flow model of the island-wide aquifer system using the most up-to-date information on the hydrology and geology of Long Island. New information is being gleaned from deep monitoring wells being drilled as part of this project. Information about water levels and sediment type, depth, and thickness will be used to update the current understanding of the island's hydrology and geology, and will be represented mathematically in the groundwater-flow model. This model will be used to evaluate different water-resource management strategies to help inform plans for a sustainable future. Looking forward, the model could also help find the amount of water that is unfit for use because of poor water quality.

\section{Long-Term Monitoring}

The USGS has been monitoring water quality, groundwater level, tide elevation, and streamflow in Long Island and New York City for decades. These data help make decisions about water resources throughout the region. These data are also critical to develop and maintain the groundwater-flow model that, in turn, can be used by water-resource managers to assess the sustainability of Long Island's aquifer system.

Upgrades to the USGS data-collection platforms and groundwater-monitoring network to near-real-time would help water-resource managers make up-to-the-minute decisions. Moreover, commitment to support the data collection needed to assess long-term changes in hydrologic conditions would enhance understanding of the effects of climate change and how to manage them.

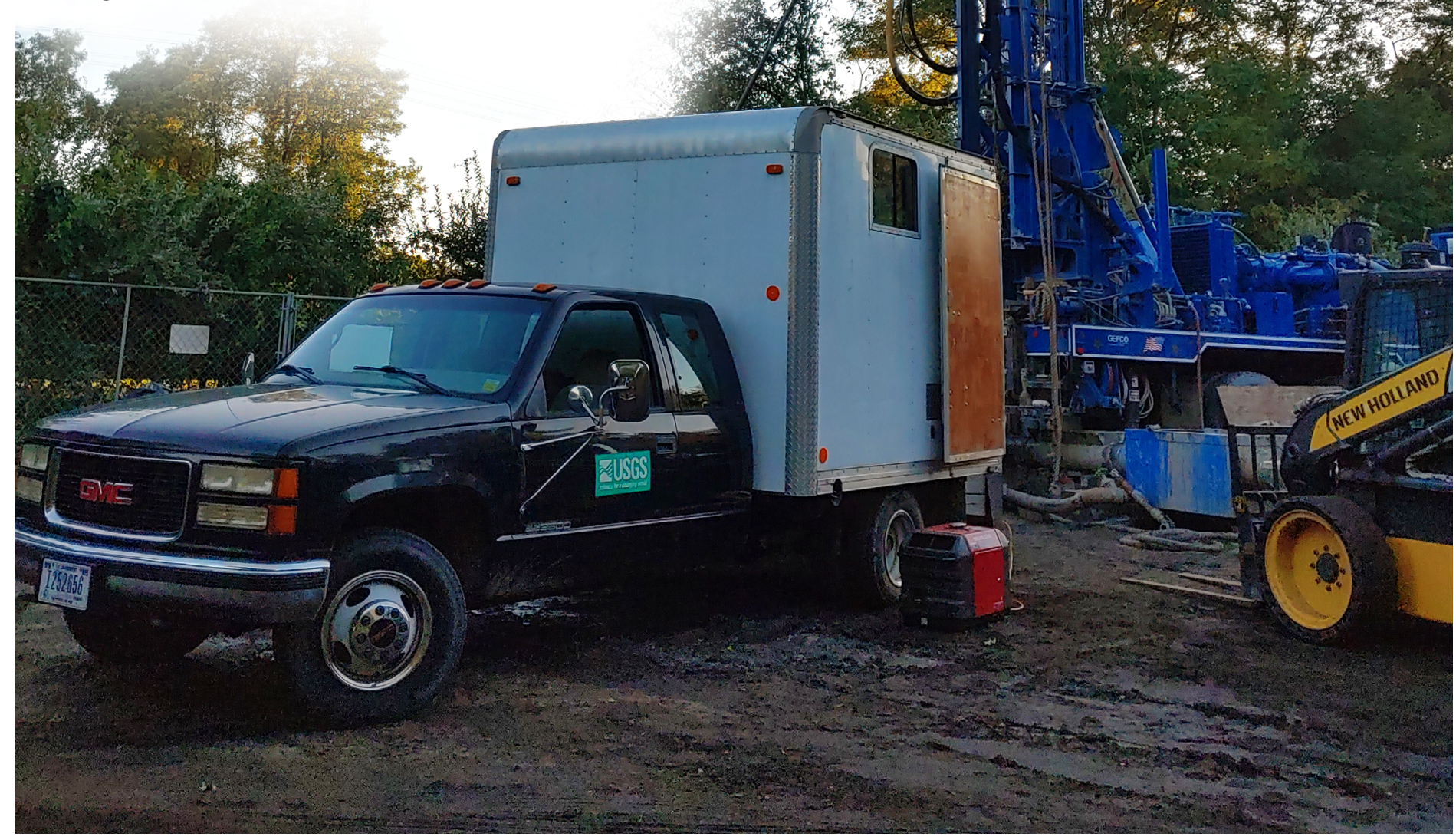

A drill rig and geophysical logging at a groundwater-monitoring site; photograph by the U.S. Geological Survey. 


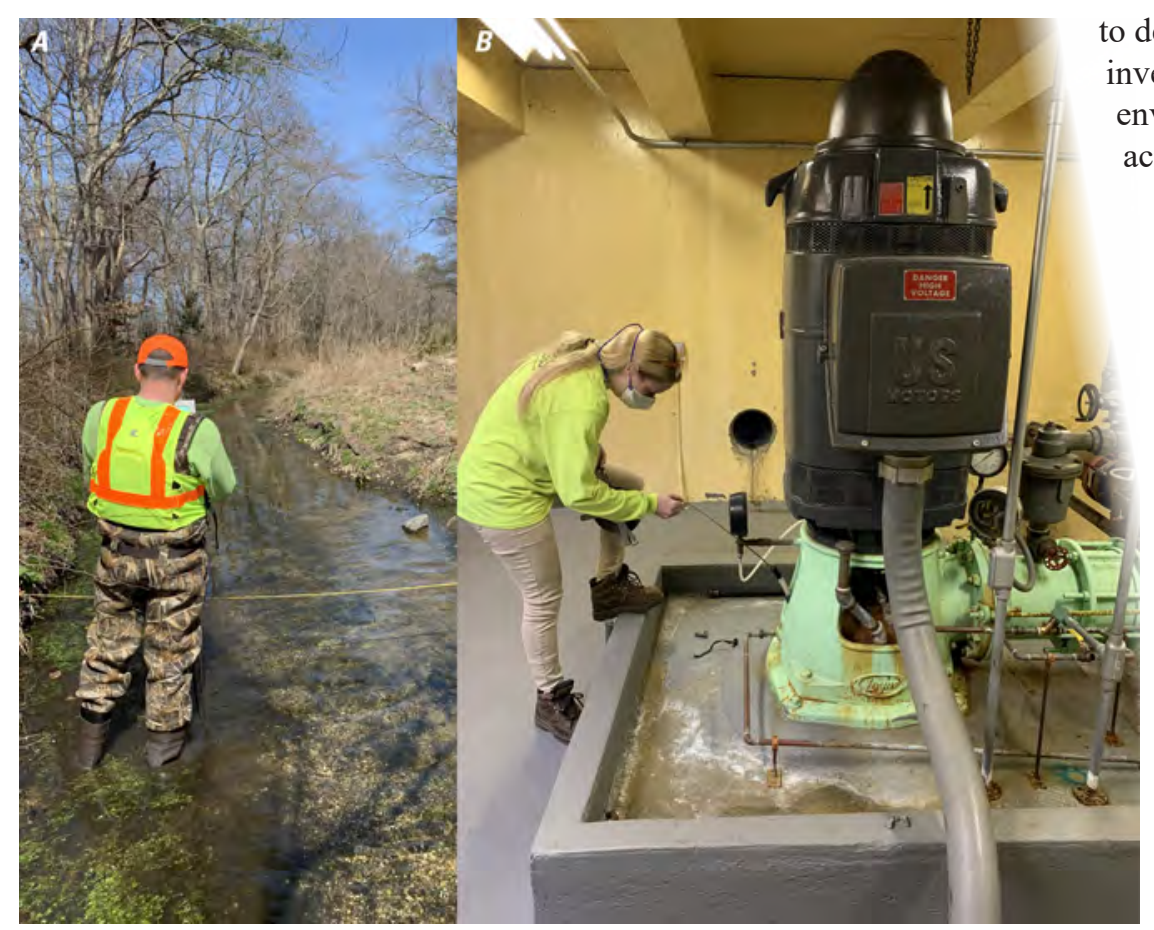

Measurements of $A$, streamflow; and $B$, groundwater levels; photographs by the U.S. Geological Survey.

\section{Nutrients}

Nutrients like nitrogen and phosphorus are known to contaminate the Long Island aquifer system. They are commonly used as fertilizers in agriculture and on suburban lawns, and are released from domestic septic systems. Nutrient contamination causes algal growth (eutrophication) in ponds, streams and coastal waters as groundwater flows through the aquifer and exits to these surface waters, and ultimately flows downstream into water bodies such as Long Island Sound, Peconic Bay, and Great South Bay.

Understanding the fate and transport of excess nutrients and the ability of management interventions to reduce nutrient loads from groundwater will be critical to restore and protect these resources. The USGS groundwater-flow model provides an important foundation to design and evaluate the effectiveness of nutrient-management strategies.

Two ongoing USGS studies are using the in-development island-wide groundwater-flow model to measure the movement of nitrogen to Peconic Bay and Long Island Sound. Results from these studies will provide the information needed to make a long-term strategy to deal with legacy and future nutrient contamination, which will help to restore and protect these valuable coastal resources.

Excess nutrients discharged to coastal bays may result in harmful algal blooms and can substantially alter the coastal ecology. Groundwater-flow models coupled with hydrodynamic and water-quality models can help plan the timing and area of best management practices (also known as BMPs) to minimize the effects of nitrogen from groundwater discharge on the coastal ecosystem. The USGS continues to develop cutting-edge groundwater-flow models and investigate harmful algal blooms in fresh and saltwater environments to meet the needs of resource managers across the island.

\section{Per- and Polyfluoroalkyl Substances and 1,4-Dioxane}

\section{Synthetic chemicals like PFAS and}

1,4-dioxane have been used in a variety of industries across Long Island, and recent evidence shows that exposure to these chemicals can affect human and ecological health. Groundwater samples collected from a subset of groundwater wells across Long Island with state-of-the-science field methods and laboratory techniques were analyzed for PFAS and 1,4-dioxane.

The results of these chemical analyses show that at least a few PFAS chemicals, or 1,4-dioxane, or both were in every sampled well. In some cases, these compounds were present in amounts unsafe for drinking based on the regulatory limits set by New York State.

Sampling the entire Long Island aquifer system for these chemicals is expensive, and there are a limited number of groundwater wells available for sampling, which makes it difficult to understand the threats of these chemicals. However, a recently completed USGS modeling exercise has shown that machine learning can help predict the distribution of synthetic 1,4-dioxane in the Long Island aquifer system. In the future, the model could be improved by sampling more areas.

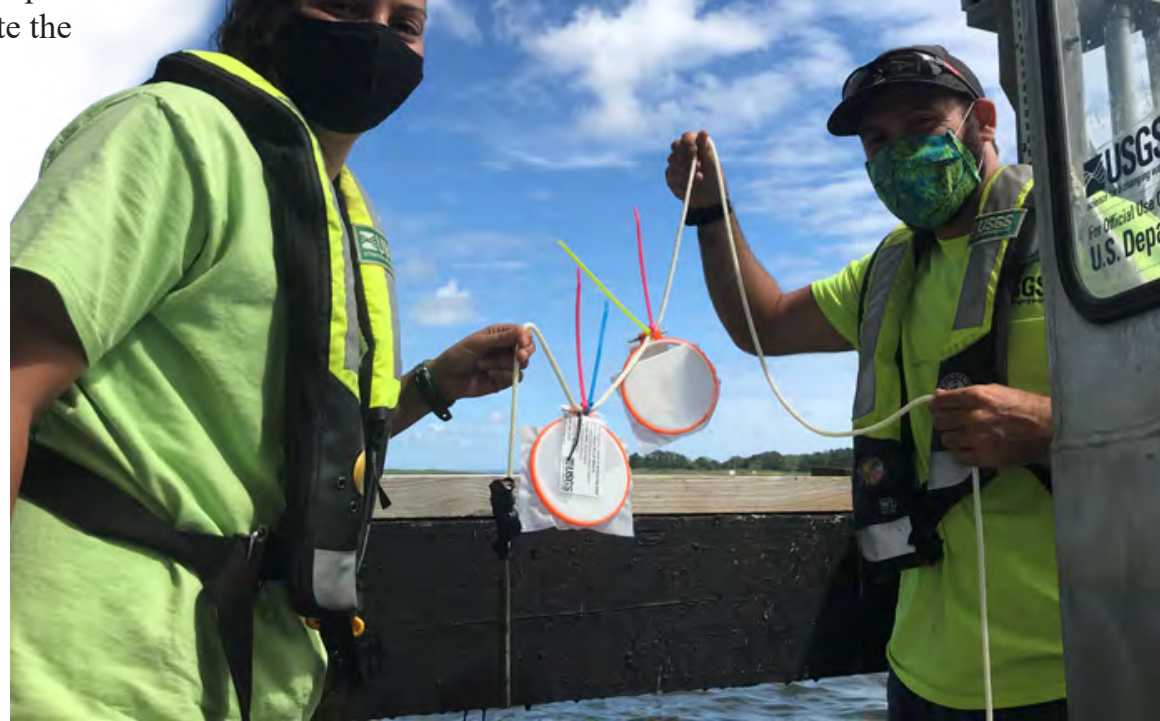

Passive samplers being used to detect harmful algal bloom toxins; photograph by the U.S. Geological Survey. 


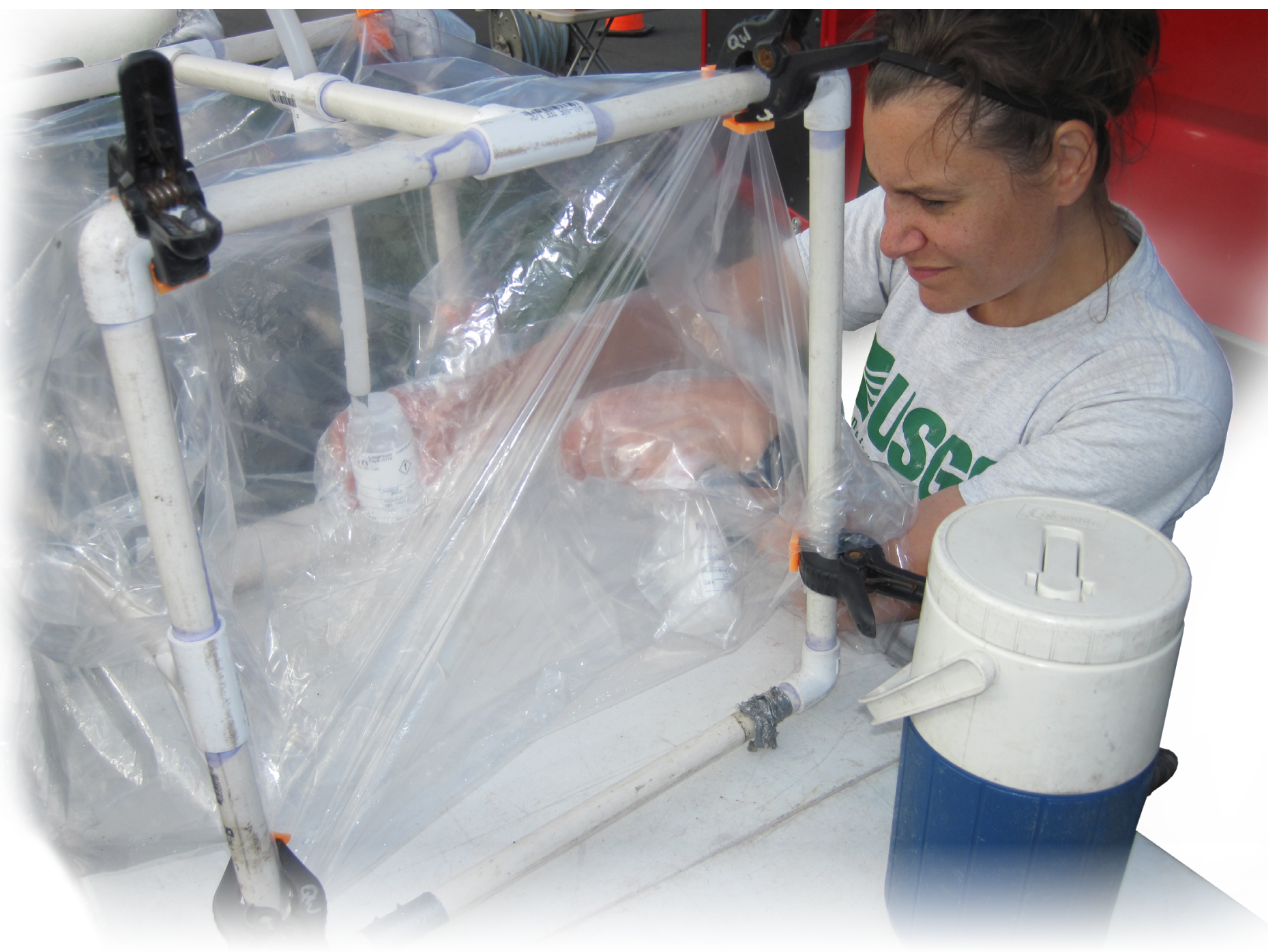

Collection of a water sample; photograph by the U.S. Geological Survey.

\section{Summary}

Clean water is essential for life on Long Island. Safeguarding the quality and quantity of water in the island's sole-source aquifer system requires a unified, multidisciplinary approach. High-quality and near real-time scientific data collection and analyses support state-of-the-science numerical and machine learning models, which are increasingly used to make essential decisions about water-resource management. These models, in turn, will help guide future data needs for areas that are the most vulnerable to water quantity or quality problems. These models provide information that can then help waterresources managers meet human needs while minimizing negative effects to the island's environment and coastal ecosystems.

\section{Reference Cited}

U.S. Environmental Protection Agency, 2020, Overview of the drinking water sole source aquifer program: U.S Environmental Protection Agency web page, accessed July 30, 2021, at https://www.epa.gov/dwssa/overview-drinking-watersole-source-aquifer-program.
By Robert F. Breault,

John P. Masterson,

Christopher E. Schubert, and

Liv M. Herdman

For more information, contact:

Director, New York Water Science Center

U.S. Geological Survey

425 Jordan Road

Troy, NY 12180-8349

dc_ny@usgs.gov

or visit our website at

https://www.usgs.gov/centers/ny-water

Publishing support provided by the

Pembroke Publishing Service Center 